\title{
Two years results of electronic brachytherapy for basal cell carcinoma
}

\author{
Rosa Ballester-Sánchez!, Olga Pons-Llanas², Cristian Candela-Juan³, Blanca de Unamuno-Bustos', \\ Francisco Javier Celada-Alvarez², Alejandro Tormo-Mico², Jose Perez-Calatayud ${ }^{3}$, Rafael Botella-Estrada' \\ 'Dermatology Department, ${ }^{2}$ Radiotherapy Department, ${ }^{3}$ Radiation Physics Department, La Fe University and Polytechnic Hospital, Valencia, \\ Spain
}

\begin{abstract}
Purpose: The use of radiation therapy (RT) for non-melanoma skin cancer (NMSC) has been changing throughout the last century. Over the last decades, the use of radiotherapy has surged with the development of new techniques, applicators, and devices. In recent years, electronic brachytherapy (eBT) devices that use small x-ray sources have been introduced as alternative to radionuclide dependence. Nowadays, several devices have been incorporated, with a few series reported, and with a short follow-up, due to the recent introduction of these systems. The purpose of this work is to describe the clinical results of our series after two years follow-up with a specific eBT system.

Material and methods: This is a prospective single-center, non-randomized pilot study, to assess clinical results of electronic brachytherapy in basal cell carcinoma using the Esteya ${ }^{\circledR}$ system. In 2014, 40 patients with 60 lesions were treated. Patient follow-up on a regular basis was performed for a period of two years.

Results: Twenty-six patients with 44 lesions achieved two years follow-up. A complete response was documented in $95.5 \%$ of cases. Toxicity was mild (G1 or G2) in all cases, caused by erythema, erosion, or alopecia. Cosmesis was excellent in $88.6 \%$ of cases, and good in the rest. Change in pigmentation was the most frequent cosmetic alteration.

Conclusions: This work is special, since the equipment's treatment voltage was $69.5 \mathrm{kV}$, and this is the first prospective study with long term follow-up with Esteya ${ }^{\circledR}$. These preliminary report show excellent results with less toxicity and excellent cosmesis. While surgery has been the treatment of choice, certain patients might benefit from eBT treatment. These are elderly patients with comorbidities or undergoing anticoagulant treatment as well as those who simply refuse surgery or might have other contraindications.

Key words: basal cell carcinoma, electronic brachytherapy, skin cancer.

\section{Purpose}

The use of radiation therapy (RT) for non-melanoma skin cancer (NMSC) has been changing during the last century. The incorporation of new technologies over the time has increased the setting of radiotherapeutic treatment options. The change in regulations and restrictions for the use of ionizing radiation also has adapted its procedure. At the same time, the development of Mohs surgery, its inclusion in dermatologic practice, and its high cure rates led to an increase in its use for treating NMSC. Nevertheless, over the last decades, the use of radiotherapy has increased with the development of new techniques, applicators, and devices.

Since the early days of RT, ionizing radiation has been used for NMSC. Its first use dates back to 1903 when radium plaques were successfully applied to a facial basal cell carcinoma [1]. With the discovery of $\mathrm{X}$-rays in the late $19^{\text {th }}$ century, X-ray devices were increasingly being used for treatment of skin cancer over the next decades. Initially, using low-energy radiation appliances like Grenz ray devices for premalignant lesions, later replaced by superficial therapy and orthovoltage devices for skin cancers. With the development of linear accelerators in the late 1950s, electron beam therapy was introduced. Treatment with electron beams is also being referred to as teleradiotherapy, because the source of radiation and the target tissue are distant. With this linear accelerator, daily treatments over 5-7 weeks are needed. Brachytherapy (BT) is a targeted type of RT delivered within the tumor (interstitial), within the cavity (intracavitary), or adjacent to the tumor as in skin surface BT. Most of the early BT was delivered with low-dose-rate (LDR) or medium-dose-rate sources (MDR). By 1970, the concept of high-dose-rate (HDR) was introduced; radiation was delivered at a rate of 12 Gy per hour or higher. This allowed shorter treatments, favoring especially elderly patients [2]. Moreover, a robotic controller improved radiation protection and simplified the 
delivery of the source. Radiobiological studies concluded that effectiveness of these treatment protocols was the same without increasing toxicity [3]. During the 1980s, the concept of hypofractionation was introduced; more precise radiation technologies made it possible to deliver higher dose to the lesions in each fraction while surrounding healthy tissue was spared, resulting in less number of sessions and shorter total time of treatment [4]. In the last decades of the $20^{\text {th }}$ century, additional research and clinical experience led to the incorporation of hypofractionated regimens using brachytherapy with $\operatorname{Ir}^{192}$ sources with high cure rates [5,6, $7,8,9,10,11]$. Brachytherapy positions of radiation source, often $\operatorname{Ir}^{192}$ is very close to a lesion. To individualize tumor characteristics, radiation surface molds and interstitial catheters are used to position the isotope and deliver ionizing radiation to the lesion. After the 1960s, several studies were published describing clinical outcome using HDR brachytherapy in combination with standardized surface molds, flaps, or applicators $[5,6,7,12]$ that are still being employed. Recent introduction of electronic brachytherapy (eBT) devices that use small x-ray sources [13] has provided an alternative to the use of isotopes. As of today, several devices have been incorporated, such as $\operatorname{Xoft}^{\circledR}$ Axxent $^{\circledR}$, Zeiss ${ }^{\circledR}$ INTRABEAM ${ }^{\circledR}$, and Elekta ${ }^{\circledR}$ Esteya ${ }^{\circledR}$, with a few series reported, and with a short follow-up, due to the recent introduction of these systems [14].

The Hospital Universitario y Politécnico La Fe has treated 40 patients with Esteya ${ }^{\circledR}$ eBT (Nucletron, an Elekta company, Elekta Brachytherapy, Veenendaal, The Netherlands) since 2014, and has published some articles on different aspects of this treatment such as commissioning and periodic tests [15], dosimetric characteristics [16,17,18], clinical implementation [19], depth determination [20], use of dermoscopy for lateral margins [21], and efficacy and safety [22]. The purpose of this work is to describe the clinical results of our series after two years of maximum follow-up.

\section{Material and methods}

\section{Description of Esteya ${ }^{\circledR}$ Electronic Brachytherapy System}

Esteya ${ }^{\circledR}$ Electronic Brachytherapy System (Elekta Brachytherapy) was specifically developed for skin surface lesions and has been commercially available since 2013 . The system consists of a control panel with planning software, a treatment unit, and a set of circular surface applicators of different diameters: $10 \mathrm{~mm}, 15 \mathrm{~mm}, 20 \mathrm{~mm}, 25 \mathrm{~mm}$, and $30 \mathrm{~mm}$. The treatment unit contains a collimated miniature X-ray source with a voltage of $69.5 \mathrm{kV}$. The beam current has a default setting of $1.6 \mathrm{~mA}$, which is automatically changed to $1.0 \mathrm{~mA}$ for treatment fractions smaller than $4 \mathrm{~Gy}$, and to $0.5 \mathrm{~mA}$ for prescription doses below $2 \mathrm{~Gy}$. The treatment time for each field, which varies between 2 and 3 minutes, is automatically calculated by the system, once the prescription dose has been entered by the user.

\section{Study design}

In 2014, 40 patients with 60 lesions were treated with Esteya ${ }^{\circledR} \mathrm{eBT}$. All patients had a diagnosis of basal cell carcinoma, superficial or nodular type, confirmed by biopsy.
Two $\mathrm{cm}$ maximum diameter and $4 \mathrm{~mm}$ maximum depth were established based on technical requirements. Tumor depth was determined by high frequency ultrasonography (HFUS) and histopathology [20]. Only T1 and T2 stages (according to AJCC 2010) [23] were included. The methodology of this study has been detailed in previous articles $[19,22]$. The protocol was approved by the Ethics Committee of Clinical Research of the Hospital Universitario y Politécnico La Fe. All patients or legal guardians signed a written informed consent.

\section{Treatment}

The clinical target volume (CTV) was established by adding a $5 \mathrm{~mm}$ lateral margin to the gross tumor volume (GTV), which was clinically determined and confirmed with the use of a dermoscope [21]. The smallest diameter applicator that covered the entire CTV was selected. To delineate the external mark to fit into the selected applicator, a specific applicator template was used [24]. The Esteya ${ }^{\circledR}$ surface applicator was placed in full contact with the tumor without air gaps. The treatment dose was prescribed at $3 \mathrm{~mm}$ for lesions with depth of $3 \mathrm{~mm}$ or less [20], and specific lesion depth was employed for prescription in the remaining lesions with a maximum of $5 \mathrm{~mm}$. All patients were treated over three weeks with two sessions per week, separated by at least 48 hours, according to the protocol used with the Valencia applicator [12]. Two different prescription doses were used: $36.6 \mathrm{~Gy}$ ( 6 fractions of $6.1 \mathrm{~Gy}$ ), and $42 \mathrm{~Gy}$ ( 6 fractions of $7 \mathrm{~Gy}$ ). The rationale of these two fractionations was previously discussed [22,25]. Treatment time was automatically calculated by the console, once dose, applicator size and depth were introduced by the operator.

\section{Follow-up and end points}

Patient follow-up on a regular basis was performed for a period of two years. Patients were seen for follow-up at 2 and 6 weeks after treatment and at 3, 6, 12, and 24 months. Clinical and dermoscopic photographs were taken at each visit. A punch biopsy was planned at 6 months after treatment if there was any clinical suspicion of persistence, or at any moment after 6 months if there was any suspicion of recurrence. Any BCC that did not completely disappear, based on clinical or dermoscopic examination, in the period of 6 months after radiation, was considered as a persistence. On the other hand, any reappearance of a sign of BCC after a complete response was considered as a relapse.

Patient demographics and lesion characteristics were recorded. End points included efficacy, toxicity, and cosmetic results. CTCAE v4.0 (Common Terminology Criteria for Adverse Events) toxicity scale [26] was used to assess toxicity, and a standardized cosmetic rating scale [27] was used to assess cosmesis (Table 1).

\section{Results}

\section{Patient demographics and lesion characteristics}

Forty patients with 60 lesions were included into the study. Eleven patients died (from other unrelated causes) 
Table 1. Cosmetic rating scale

\begin{tabular}{ll} 
Excellent & $\begin{array}{l}\text { No changes to slight atrophy or pigment change or } \\
\text { slight hair loss, or no changes to slight induration } \\
\text { or loss of subcutaneous fat }\end{array}$ \\
\hline Good & $\begin{array}{l}\text { Patch atrophy, moderate telangiectasia, and total } \\
\text { hair loss; moderate fibrosis but asymptomatic; } \\
\\
\text { slight field contracture with less than 10\% linear } \\
\text { reduction }\end{array}$ \\
\hline Fair & $\begin{array}{l}\text { Marked atrophy and gross telangiectasia; severe } \\
\text { induration or loss of subcutaneous tissue; field } \\
\text { contracture greater than } 10 \% \text { linear measurement }\end{array}$ \\
\hline Poor & Ulceration or necrosis
\end{tabular}

and 3 were lost to follow-up, therefore we have analyzed the results of 26 patients with 44 lesions with a follow-up of 2 years.

Fourteen women with 25 lesions (56.8\%) and 12 men with 19 lesions (43.2\%) achieved two year follow-up after electronic brachytherapy treatment for basal cell carcinoma. The mean age was 69.2 years and it ranged from 57 to 86 . There were fourteen lesions $(46.7 \%)$ with a phototype 2, and 30 lesions (53.3\%) with a phototype 3. Seven patients $(18.9 \%)$ were undergoing antiplatelet or anticoagulant treatment that could be a contraindication for choosing surgery. The mean diameter of lesions was $13.25 \mathrm{~mm}$ (range, 5-18). Twenty-four lesions (54.6\%) were pigmented and none ulcerated. Twenty-nine basal cell carcinomas $(65.9 \%)$ corresponded to a superficial type, and $15(34.1 \%)$ to a nodular type. The majority of patients $(97.7 \%)$ had a T2 stage (AJCC 2010) tumor [23]. The mean maximum depth was $1.44 \mathrm{~mm}$ measured by histopathology (range, 0.26-3.2), and $1.23 \mathrm{~mm}$ measured by HFUS (range, $0.1-3.7)$. Four sizes of skin applicator were used: $15 \mathrm{~mm}$ in 2 lesions (4.6\%), $20 \mathrm{~mm}$ in 11 lesions (25\%), $25 \mathrm{~mm}$ in 17 lesions (38.6\%), and $30 \mathrm{~mm}$ in 14 lesions (31.8\%). Dose prescription depth was $3 \mathrm{~mm}$ in 42 cases $(95.4 \%)$, and $4 \mathrm{~mm}$ in $2(4.6 \%)$.

\section{Efficacy, toxicity, and cosmetic results}

Results by lesions are shown in Table 2. Forty-two lesions $(95.5 \%)$ achieved a complete response, and 2 a partial response $(4.5 \%)$. One patient treated with 36.6 Gy persisted at 6 months, and the other patient was treated with 42 Gy and recurred at 12 months after treatment. Both patients were rescued with surgery; recurrence being histologically confirmed. All treated areas showed some degree of acute toxicity: 14 G1 (31.8\%) and 30 G2 (68.2\%). Acute toxicity was erythema (31.8\%), ulceration (53.3\%), or alopecia $(4.6 \%)$. No cases of G3 or G4 toxicity were observed.

Cosmetic results were evaluated as excellent in 39 cases $(88.6 \%)$ and good in $5(11.4 \%)$. No fair or poor cases were observed. Cosmetic alterations were due to alopecia in 3 cases $(18.75 \%)$, pigmentation changes in 30 cases $(66.7 \%)$, or telangiectasia in 4 cases $(9.1 \%)$. No cases of ulceration, necrosis, contracture, or induration were observed.

There were no differences between different schedules employed in terms of toxicity or cosmesis.
Table 2. Efficacy, toxicity, and cosmetic results (showed by lesions)

\begin{tabular}{lccc} 
Factors & $\begin{array}{c}36.6 \mathrm{~Gy} \\
(n=26)\end{array}$ & $\begin{array}{c}42 \mathrm{~Gy} \\
(n=18)\end{array}$ & $\begin{array}{c}\text { Total, } \\
n(\%)\end{array}$ \\
\hline Efficacy & 1 & 1 & $2(4.5)$ \\
\hline Partial response & 25 & 17 & $42(95.5)$ \\
\hline Complete response & & & \\
\hline Acute toxicity & & & $14(31.8)$ \\
\hline G1 & 6 & 8 & $14(31.8)$ \\
\hline G2 & 20 & 10 & $30(53.3)$ \\
\hline Erythema & 0 & 2 & $2(4.6)$ \\
\hline Ulceration & & & \\
\hline Alopecia & & & $5(11.4)$ \\
\hline Cosmesis & 2 & 1 & $3(18.75)$ \\
\hline Good & 19 & 11 & $30(66.7)$ \\
\hline Excellent & 2 & $4(9.1)$ \\
\hline Alopecia & & & $39(88.6)$ \\
\hline Pigmentation changes & $19.2)$ \\
\hline Telangiectasias & & & \\
\hline
\end{tabular}

Source: National Comprehensive Cancer Network guidelines 2013 of Basal Cell Skin Cancer

\section{Discussion}

Radiation therapy for NMSC has seen significant changes during the last century. Different radiation therapy techniques have been used to treat NMSC. It includes superficial X-rays, orthovoltage X-rays, megavoltage X-rays, electron beam irradiation, and radionuclide-based BT [13]. Electronic brachytherapy have become increasingly popular in the last 5 years.

Electronic brachytherapy is currently a topic of discussion amongst dermatologists. The most common criticisms are the little data on long-term outcomes and the lack of randomized trials comparing with surgery. Therefore, long-term studies and appropriate use of criteria for eBT will be necessary to position this new technology.

Electronic brachytherapy has some advantages over external RT. Firstly, less normal tissue is irradiated compared to teletherapy treatments due to close contact with the tumor and minimal radiation leakage as a result of the improved shielding. Furthermore, smaller margins can be used due to more precise treatment. Unlike other devices, molds are not necessary for this small lesions with eBT, and the use of standardized applicators simplifies the procedure. A bolus is not necessary either, as the electrons facilitates the treatment. Moreover, shorter treatment time is needed per session and for overall treatment. Finally, the devices are small and mobile, and minimal shielding is required because of the low energy; no radioactive isotope is used $[13,14]$. Comparison between Esteya ${ }^{\circledR}$ device with other series with radioactive sources have been already revised in a previous work [25]. 
Several devices are currently available, such as Xoft Axxent $^{\circledR}$ (Xoft Inc., San Jose, CA, USA), Zeiss INTRABEAM $^{\circledR}$ (Oberkochen, Germany), and Elekta Esteya ${ }^{\circledR}$ (The Netherlands). All three incorporate an X-ray source. Esteya ${ }^{\circledR}$ is specifically designed for cutaneous tumors; the other systems may also be used for other tumor types when used in combination with different applicators (intracranial, breast, or gynecological). Aspects of dosimetry and clinical practice of skin brachytherapy with these devices has been reported by The American Brachytherapy Society in the working group report $[13,14]$. Each device has different sizes of surface applicators. Axxent ${ }^{\circledR}$ uses 10, 20,35 , and $50 \mathrm{~mm}$ diameter field size, and the dose can be prescribed between $2-5$ mm depth. INTRABEAM ${ }^{\circledR}$ uses 10, 20, 30, and $40 \mathrm{~mm}$ diameter field size. Esteya ${ }^{\circledR}$ can be prescribed between 3-5 $\mathrm{mm}$ depth and has 5 applicators with of a field size of $10,15,20,25$, and $30 \mathrm{~mm}$ in diameter. Esteya ${ }^{\circledR}$ has several design characteristics that make it an excellent tool for treating skin cancer: the Tungsten shielding reduces radiation to healthy tissue to a minimum [28], overdose at the skin surface is kept to a minimum, workflow is extremely simple, and the source has a guaranteed life time of at least 4000 fractions.

Zeiss INTRABEAM ${ }^{\circledR}$ has been commercially available before 2013, but no clinical outcomes about cutaneous treatments have been published. Xoft Axxent ${ }^{\circledR}$ is the longest in the market, since 2009, therefore it has the largest and longest series published until now. Different groups in the USA have been using it for treating NMSC, and several clinical series have been reported, all of them using the same protocol: 40 Gy in 8 fractions, delivered twice weekly, with a standard depth prescription of $3 \mathrm{~mm}$. Bhatnagar [29] has treated 282 lesions in 187 patients with NMSC (53\% basal cell carcinoma). He reported a $98.7 \%$ local control rate in 238 lesions, with a median follow-up of 12.5 months. Most patients were satisfied with the treatment. Dogget et al. [1] have treated 524 NMSC (BCC, SCC, or SCC in situ) with more than 99\% local control rate. Paravati et al. [30] reported 127 patients with 154 NMSC (149 BCC) with a $98.7 \%$ control rate, with a median of 16 months follow-up. In all cases, the authors referred to local control rate as the absence of signs of tumor at the last examination, without histopathological confirmation. Cosmesis was good to excellent in most cases in all series. Hypopigmentation was the most common late toxicity, appearing in $7.9 \%$ of cases [29]. Elekta Esteya ${ }^{\circledR}$ has been available since 2013. Having treated the very first patients with this device, we believe to have the longest follow-up. Efficacy at 6 months has already been reported [22], but now we report patients with long-term follow-up (over 2 years post-treatment). We have used two different prescription doses, 36.6 and 42 Gy in 6 fractions, twice a week, during three weeks. A 95.5\% local control rate was achieved with good to excellent cosmesis in all cases. Pigmentation changes constituted the most common cosmetic alteration.

\section{Conclusions}

Electronic brachytherapy for NMSC is nowadays being employed in clinical practice, and it results begins to be published. This work is unique in that the treatment voltage is $69.5 \mathrm{kV}$ rather than $50 \mathrm{kV}$ seen in Xoft Axxent ${ }^{\circledR}$ and Zeiss INTRABEAM ${ }^{\circledR}$. This is also the first prospective study with long term follow-up with Esteya ${ }^{\circledR}$. There are clear advantages of eBT over traditional RT with radioisotopes. The treatment devices are mobile, do not require shielding, or storing of radioisotopes. There is less total body dose and lower peripheral dose. While surgery remains the first choice as a treatment, some patients could benefit from eBT, especially elderly patients, those with comorbidities, or undergoing anticoagulant treatment as well as those who refuse surgery or in whom it is contraindicated. Large series with long-term follow-up and high quality clinical trials comparing eBT with surgery are essential in order to ascertain the adequate position of eBT within the armamentarium of NMSC.

\section{Acknowledgements}

This study was supported in part by Nucletron (an Elekta Company, Veenendaal, The Netherlands) by Generalitat Valenciana (Project PROMETEOII/2013/010) and by Spanish Government under Project No. FIS2013-42156.

\section{Disclosure}

Authors report no conflict of interest.

\section{References}

1. Doggett S, Willoughby M, Willoughby C et al. Incorporation of electronic brachytherapy for skin cancer into a community dermatology practice. J Clin Aesthet Dermatol 2015; 8: 28-32.

2. Hall E. Radiation dose-rate: a factor of importance in radiobiology and radiotherapy. Br J Radiol 1972; 45: 81-97.

3. Manimaran S. Radiobiological equivalent of low/high dose rate brachytherapy and evaluation of tumor and normal responses to the dose. Radiat Med 2007; 25: 229-235.

4. Fowler JF. The linear-quadratic formula and progress in fractionated radiotherapy. Br J Radiol 1989; 62: 679-694.

5. Köhler-Brock A, Prager W, Pohlmann S et al. The indications for and results of HDR afterloading therapy in diseases of the skin and mucosa with standardized surface applicators (the Leipzig applicator). Strahlenther Onkol 1999; 175: 170-174 [Article in German].

6. Guix B, Finestres F, Tello JI et al. Treatment of skin carcinomas of the face by high-dose-rate brachytherapy and custom-made surface molds. Int J Radiat Oncol Biol Phys 2000; 47: 95-102.

7. Gauden S. HDR brachytherapy for the treatment of skin cancers using standard surface applicators. Brachytherapy 2008; 7: S159.

8. Piro F. HDR brachytherapy for skin cancers. Brachytherapy 2008; 7: S128.

9. Sabbas AM, Kulidzhanov FG, Presser J et al. HDR brachytherapy with surface applicators: technical considerations and dosimetry. Technol Cancer Res Treat 2004; 3: 259-267.

10. Alam M, Nanda S, Mittal BB et al. The use of brachytherapy in the treatment of nonmelanoma skin cancer: A review. J Am Acad Dermatol 2011; 65: 377-388.

11. Musmacher J, Ghaly M, Satchwill K. High dose rate brachytherapy with surface applicators: treatment for nonmelanomatous skin cancer. J Clin Oncol 2006; 24: 5543.

12. Tormo A, Celada F, Rodriguez S et al. Non-melanoma skin cancer treated with HDR Valencia applicator: clinical outcomes. J Contemp Brachytherapy 2014; 6: 167-172. 
13. Ouhib Z, Kasper M, Perez Calatayud J et al. Aspects of dosimetry and clinical practice of skin brachytherapy: The American Brachytherapy Society working group report. Brachytherapy 2015; 14: 840-858.

14. Kasper ME, Chaudhary AA. Novel treatment options for nonmelanoma skin cancer: Focus on electronic brachytherapy. Med Devices Evid Res 2015; 8: 493-502.

15. Candela-Juan C, Niatsetski Y, Ouhib Z et al. Commissioning and periodic tests of the Esteya ${ }^{\circledR}$ electronic brachytherapy system. J Contemp Brachytherapy 2015; 7: 189-195.

16. Garcia-Martinez T, Chan JP, Perez-Calatayud J et al. Dosimetric characteristics of a new unit for electronic skin brachytherapy. J Contemp Brachytherapy 2014; 6: 45-53.

17. Candela-Juan C, Vijande J, García-Martínez T et al. Comparison and uncertainty evaluation of different calibration protocols and ionization chambers for low-energy surface brachytherapy dosimetry. Med Phys 2015; 42: 4954-4964.

18. Ibanez-Rosello B, Bautista-Ballesteros JA, Bonaque J et al. Failure mode and effects analysis of skin electronic brachytherapy using Esteya ${ }^{\circledR}$ unit. J Contemp Brachytherapy 2016; 8: 518-524.

19. Pons-Llanas O, Ballester-Sánchez R, Celada-Álvarez FJ et al. Clinical implementation of a new electronic brachytherapy system for skin brachytherapy. J Contemp Brachytherapy 2014; 6: 417-423.

20. Ballester-Sánchez R, Pons-Llanas O, Llavador-Ros M et al. Depth determination of skin cancers treated with superficial brachytherapy: Ultrasound vs. histopathology. I Contemp Brachytherapy 2014; 6: 356-361.

21. Ballester Sánchez R, Pons Llanas O, Pérez Calatayud J et al. Dermoscopy margin delineation in radiotherapy planning for superficial or nodular basal cell carcinoma. Br J Dermatol 2015; 172: 1162-1163.

22. Ballester-Sánchez R, Pons-Llanas O, Candela-Juan C et al Efficacy and safety of electronic brachytherapy for superficial and nodular basal cell carcinoma. J Contemp Brachytherapy 2015; 7: 231-238

23. Cancer staging of cutaneous nonmelanoma skin cancer. AJCC (American Joint Committee on Cancer).

24. Villalba SR, Perez-Calatayud MJ, Bautista JA et al. Novel simple templates for reproducible positioning of skin applicators in brachytherapy. J Contemp Brachytherapy 2016; 8: 344-348.

25. Ballester-Sánchez R, Pons-Llanas O, Candela-Juan C et al Electronic brachytherapy for superficial and nodular basal cell carcinoma: A report of two prospective pilot trials using different doses. J Contemp Brachytherapy 2016; 8: 48-55.

26. CTCAE v4.0: NIH Publication No. 09-5410.

27. Cox J, Stetz J, Pajak T. Toxicicty criteria of the Radiation Therapy Oncology Group (RTOG) and the European Organization for Research and Treatment of Cancer (EORTC). J Radiat Oncol Biol Phys 1995; 31: 1341-1346.

28. Ibanez-Rosello B, Bautista-Ballesteros J, Candela-Juan C et al. Evaluation of the shielding in a treatment room with an electronic brachytherapy unit. J Radiol Prot 2017; 37: 5-12.

29. Bhatnagar A. Clinical outcomes and patient-reported outcomes following electronic brachytherapy for the treatment of non-melanoma skin cancer. Int I Radiat Oncol Biol Phys 2016; 96: 713.

30. Paravati AJ, Hawkins PG, Martin AN et al. Clinical and cosmetic outcomes in patients treated with high-dose-rate electronic brachytherapy for nonmelanoma skin cancer. Pract Radiat Oncol 2015; 5: 659-664. 